\title{
Geoprocessing Tools for Surface and Basement Flooding Analysis in SWMM
}

\author{
Eric White, James Knighton, Gary Martens, Matthew Plourde and \\ Rajesh Rajan
}

\begin{abstract}
A geoprocessing routine was used for the development of a modified combined sewer conveyance system model to aid in defining the magnitude of basement backups and surface flooding, which often occur in older urban areas served by combined sewer systems. Detailed stage-storage relationships (including both basement and surface flooding storage) were developed utilizing standard GIS tools, a geospatial sewer network, building footprint boundaries, and a high resolution digital elevation model. In addition to representing more accurate stage-storage volumes in SWMM, the routing of surface floodwater was also simulated. Predicted peak water elevations in the conveyance system were then post-processed in GIS to determine the location within each subcatchment where basement or surface flooding was experienced. This approach, when compared to a more traditional sewer system hydraulic model, resulted in more accurate flood volume and depth calculations. Additionally, this routine produced a more accurate representation of street and building flood inundation within the study area.
\end{abstract}

\subsection{Introduction}

The new model development approach presented in this chapter was established in order to better predict surface and basement flooding from surcharged sewers within the city of Philadelphia's combined sewer system.

White, E., J. Knighton, G. Martens, M. Plourde and R. Rajan. 2013. "Geoprocessing Tools for Surface and Basement Flooding Analysis in SWMM." Journal of Water Management Modeling R246-03. doi: 10.14796/JWMM.R246-03. (C) CHI 2013 www.chijournal.org ISSN: 2292-6062 (Formerly in Pragmatic Modeling of Urban Water Systems. ISBN: 978-0-9808853-8-5) 
This system collects wastewater and stormwater from individual buildings and properties, which are connected via service laterals to sewers within each city street. These street sewers make up the branch sewer network, which is tributary to larger trunk sewers. Trunk sewers are responsible for conveying all flows from these branch sewers downstream, where all dry weather flows and a portion of wet weather flows are diverted to smaller interceptor sewers. The interceptor sewers convey the flow to one of Philadelphia's three waste water treatment plants, and the wet weather flows in excess of the interceptor sewers' capacities are freely discharged to receiving water bodies in order to relieve the system.

Based on pipe capacity calculations, together with preliminary SWMM modeling efforts, trunk sewer capacity appears to be a critical factor in many surface and basement flooding issues within the city. Due to minimum pipe size specifications that have been traditionally used by the city, small branch sewers are typically sized appropriately, not capacity-limited, and generally deliver wet weather flows efficiently to the trunk sewers.

Flow regulating structures are located at the downstream end of each trunk sewer, resulting in combined sewer overflows as the interceptor sewers (and the waste water treatment plants) become capacity limited. Therefore, under normal operating conditions, the interceptor sewers are not the cause of basement and surface flooding.

The city's sewer replacement program systematically upgrades a certain portion of the city's branch sewers each year. Any land development that has occurred after the initial installation of the sewer system is generally accounted for in the redesign of the branch sewers during sewer replacement. However, this replacement program does not regularly deal with upgrading the trunk sewers, many of which were originally installed over a century ago.

The flow capacity limitation of trunk sewers within Philadelphia has led to recurring basement backups and surface flooding in portions of the city during extreme wet weather events. In an effort to fully diagnose these problems and to be able to aid in planning a solution to these issues, hydrologic and hydraulic models of various neighborhoods are being built using the United States Environmental Protection Agency's Storm Water Management Model, Version 5.0.022 (SWMM5) (Rossman, 2010).

Previous modeling efforts resulted in a relatively simple way of estimating potential basement backups using SWMM. Peak hydraulic grade line (HGL) elevations along trunk sewers were compared to surface elevations (and estimated basement depths) in areas tributary to the trunk sewers. Thus, if flooding was predicted at a model trunk node, then all parcels within drainage areas directly tributary to that node were considered to be potentially subject to flooding. This approach is deemed appropriate for estimating basement 
flooding in flat sections of the city; however, the approach is inadequate when attempting to determine either surface flooding or basement flooding in steeper areas. In order to better identify locations that could be susceptible to surface flooding and basement backups, a new geoprocessing method was followed during project development.

Rather than invest in a full two dimensional model that would route floodwaters on the surface, a surface analysis was conducted that resulted in stage-storage curves for each model subcatchment. These stage-storage curves were represented in SWMM as storage nodes. As the HGL elevation at a given storage node rises, the storage volume representing surface and basement areas at that elevation would begin to fill. The HGL in the sewer is not able to rise further until all available storage volumes (i.e. basement and surface flooding areas) at and below the HGL elevation are full.

In addition to accounting for the volumes of floodwater, each storage node is also hydraulically connected to surrounding storage nodes. Figure 3.1 provides a conceptual diagram of how this coupled basement-surface flow system is modeled. Any particular storage unit is only able to fill to an elevation at which it is hydraulically connected with a neighboring storage node via surface flowpaths. This provides an upper limit to the HGL for each storage unit, and therefore sets an upper limit to the flooding volume available at each storage unit. If flows were still in excess of pipe capacities when a storage unit reaches its maximum volume or depth, the surface hydraulic network connecting the storage units would then begin conveying flow.

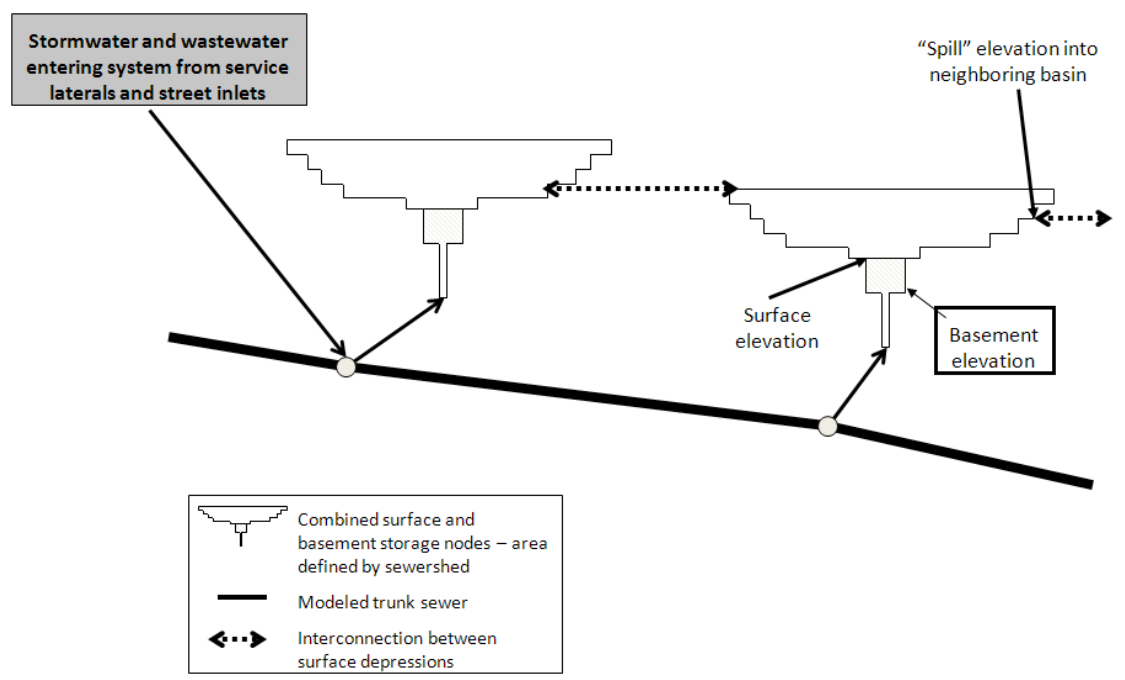

Figure 3.1 Conceptual diagram of basement/surface storage model coupled with sewer and surface flows. 


\subsubsection{Project Area Description}

The model approach described above was tested using one neighborhood in Philadelphia. The project area is served by two trunk sewers that are parallel to each other for more than 3.8 miles $(6 \mathrm{~km})$ before combining into one double barrel trunk sewer.

At the downstream end of the double barrel section, the trunk sewer enters into a single regulating structure. From simple pipe capacity calculations, it is evident that the known flooding issues in this project area are dependent upon the trunk sewer capacity, rather than any downstream boundary condition that may be set by the regulating structure.

The two trunk sewers serving this neighborhood were built in the late nineteenth century and were originally installed to encapsulate historic streams. Later, extensive development occurred in this neighborhood resulting in many buildings being constructed in the historic floodplain and, as well, on the historic streambed itself. Due to this development, and the limited size of the trunk sewers, these sewers regularly surcharge as a result of extreme wet weather events, resulting in basement backups and surface flooding, as illustrated in Figure 3.2.

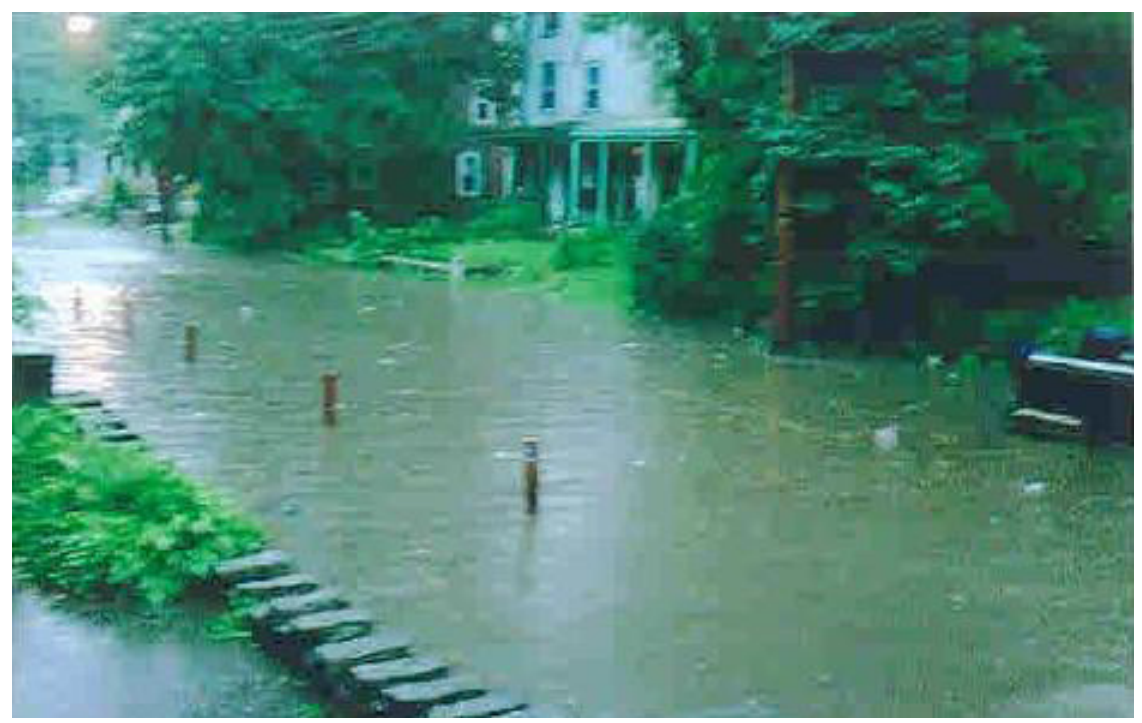

Figure 3.2 Surface flooding, due to sewer surcharging, ponding several feet deep in a localized surface depression located within the project area.

Further exacerbating the surface flooding issues are the numerous intersections that were artificially lowered in order to remove at-grade railway 
road crossings in this neighborhood. These artificial surface depressions are directly above the trunk sewers, and therefore trap surface flows that backflow out of street inlets and manholes when the sewer is surcharged during large events. Determining the depth that these depressions could be filled and where flow would be directed once these depressions over-top was an impetus for developing this new modeling approach.

\subsection{Methodology}

The techniques followed in this new modelling approach relied upon the following geospatial data regularly maintained by the City of Philadelphia:

- geospatial network of existing sewer infrastructure network;

- $\quad$ surface elevations;

- building footprints;

- land cover data; and

- soils data.

The model was developed primarily by editing a SWMM model input file (inp file) using a text editor. However the following software was also required for various processes described below:

the USEPA SWMM5 graphical user interface (GUI);

- $\quad$ ArcMAP with Spatial Analyst (ESRI);

- $\quad$ the R programming language; and

- $\quad$ spreadsheet and database management (Microsoft Excel and Microsoft Access).

\subsubsection{Hydrologic and Hydraulic Model Development}

Philadelphia's geospatial sewer system database contains the location of installed sewers within the city, and in many cases also contains pipe attributes such as slope, material, shape, and size; this is the only dataset required for the initial step of delineating each sewer's contributing area (i.e. sewershed). To develop the SWMM model, a node was initially placed at each point where a pipe attribute changed. If available, the invert elevation of this node was assigned; if unavailable, the invert elevation was interpolated from other known elevations and from design pipe slopes and offsets. An automated procedure, which relies upon the Euclidean analysis tool provided by ESRI, was used to determine the sewershed contributing to each of these nodes (ESRI, 2012). This process is analogous to the creation of Thiessen polygons; however, instead of creating polygons by assigning an area to the nearest point, Euclidean analysis determines polygons based on areas closest to a vector line, in this case defined by every conduit in the model. 
Only sewers servicing areas larger than a given threshold were ultimately modeled as SWMM conduits (see Figure 3.3). Any sewers with upstream contributing areas smaller than this threshold were removed from the model. These areas were then grouped with adjacent sewersheds to form subcatchments larger than the threshold area. Although not modeled as explicit sheds and conduits, the tributary area to the sewers that were removed were still indirectly modeled via subcatchment properties, which were adjusted during the calibration process.

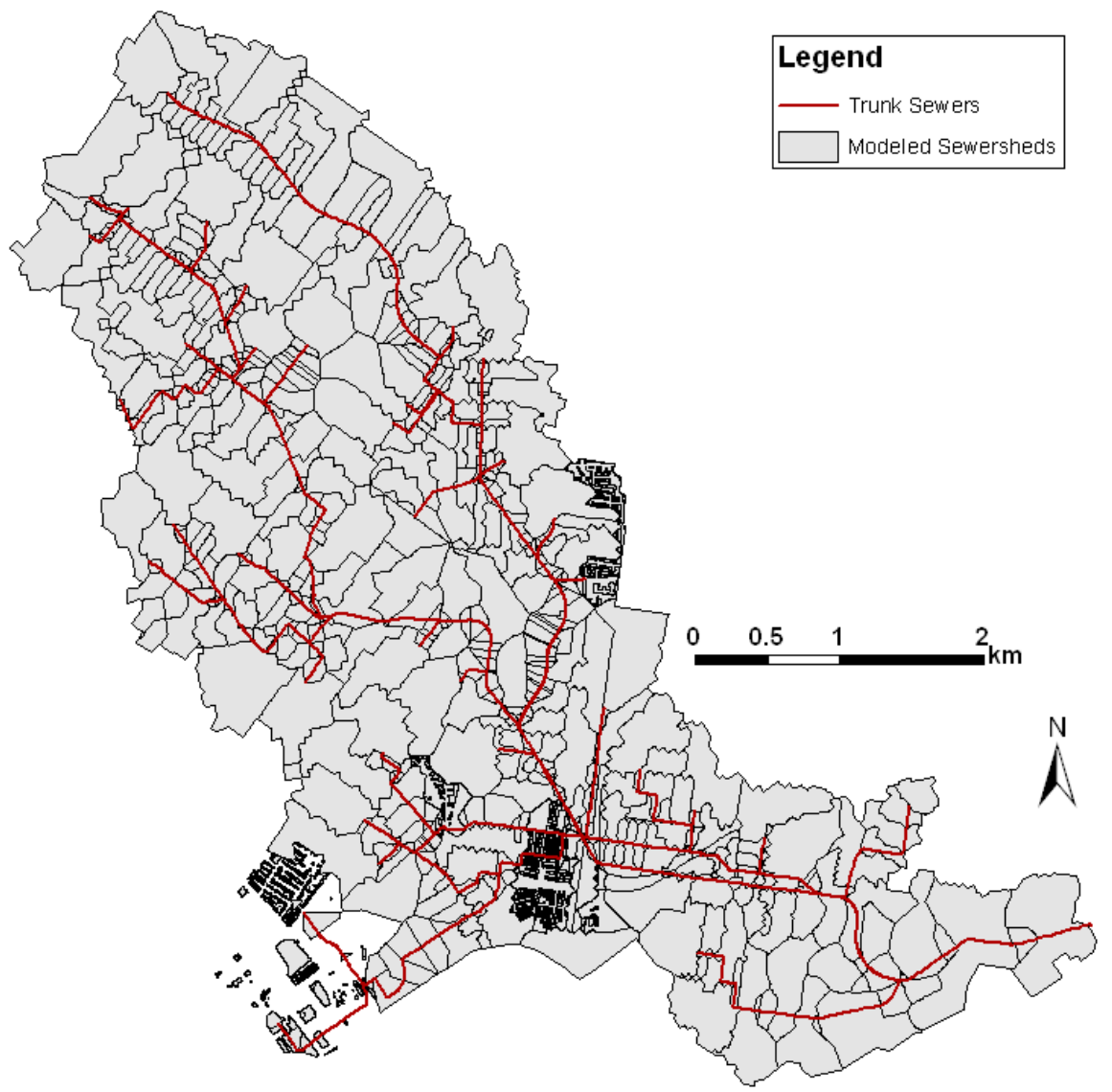

Figure 3.3 Overview of all sewers modeled as SWMM conduits with the contributing subcatchments.

Subcatchment properties required by SWMM, such as slope and impervious area, were determined from the geospatial data previously listed (Table 3.1). Some properties, such as percent of impervious area routed, 
depression storage, subcatchment width, and Green-Ampt infiltration properties were chosen to be calibration parameters. Initial values for most of these parameters were chosen to match an existing, less detailed SWMM model of this area which was developed for the Philadelphia Combined Sewer Overflow Long Term Control Plan Update (LTCPU) (Philadelphia Water Department, 2009).

Table 3.1 Subcatchment properties.

\begin{tabular}{lcccc}
\hline & Mean & Median & Minimum & Maximum \\
\hline Area & 10.9 acre $(4.4$ ha $)$ & 4.1 acre $(1.7$ ha $)$ & 0.4 acre $(0.16$ ha $)$ & 94.4 acre (37.8 ha $)$ \\
\% Impervious & $59 \%$ & $60 \%$ & $1 \%$ & $100 \%$ \\
Land Slope & $6.8 \%$ & $6.2 \%$ & $1.4 \%$ & $27.7 \%$ \\
\hline
\end{tabular}

Total area $=8.67 \mathrm{mi}^{2}\left(22.5 \mathrm{~km}^{2}\right)$

508 subcatchments in total project area

Each SWMM subcatchment was loaded directly to a storage node. Each storage node is hydraulically connected to other storage nodes via SWMM conduits. Properties for each conduit were determined from the city's geospatial sewer network database. As previously mentioned, some conduit attributes were absent from this database. In such instances, historic engineering design drawings were referenced to fill any missing data, including storage node invert elevations. Other properties for storage nodes were determined during the development of the surface model portion, which is detailed in the next section.

\subsubsection{Surface Model Development}

As stated in the previous section, runoff from each subcatchment in the SWMM model is routed to a storage node. Storage nodes, rather than junction nodes, were used so that if flooding were to occur, all storage volume available on the land surface and in basements within the subcatchments loading directly to each node would be filled as the system's HGL rises.

The following geoprocessing routine was used to systematically produce depth-area curves for these storage nodes:

1. Start with a raster digital elevation model (DEM) that has been pre-processed to minimize errors (Figure 3.4 below). The DEM maintained by the City of Philadelphia was pre-processed to remove buildings. Instead of the elevation of each building's roof, the ground elevation for each building was determined;

2. Determine the location of buildings (Figure 3.5 below);

3. Burn in basement depths to the DEM by assuming that all 
buildings have basements that extend a certain depth below the ground surface (Figure 3.6 below). Based upon previous analyses, it was assumed that the average basement in Philadelphia extends to a depth $5 \mathrm{ft}(1.52 \mathrm{~m})$ below ground level;

4. Each raster cell within the DEM must be associated with the subcatchment that it is within. To accomplish this, the DEM was converted to a point file which was then spatially joined with a polygon file of the subcatchment boundaries;

5. SWMM requires a depth-to-surface-area table for all storage nodes. To create these tables, the elevation points within each subcatchment were converted to depths relative to the invert of the subcatchment's representative storage node. The invert of each storage node was assigned during the initial hydraulic model development process, as discussed above; and

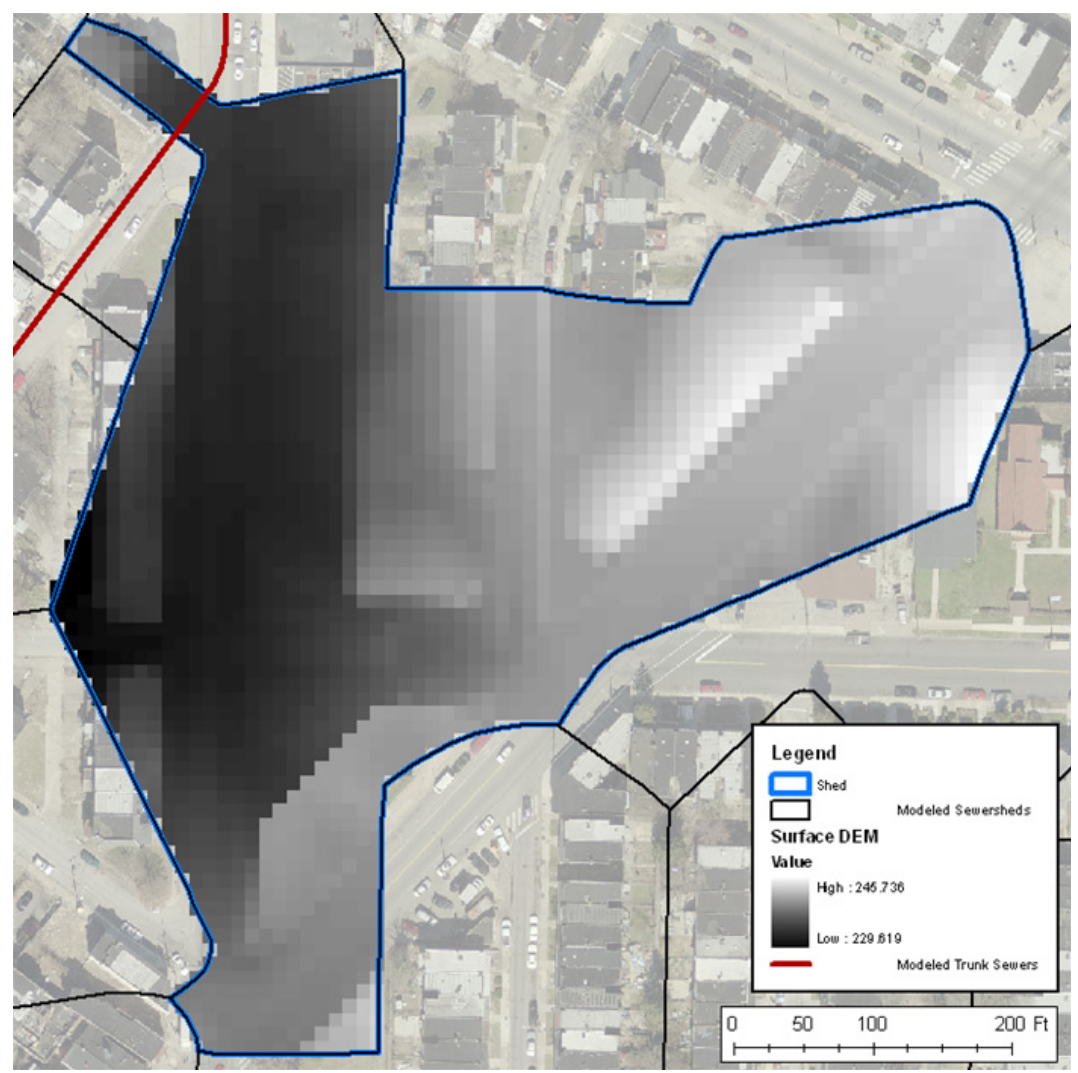

Figure 3.4 Raster DEM with building elevations filtered out. 
6. Using a program written in the programming language $\mathrm{R}$, depth-area curves were created for each subcatchment's representative storage node. This $\mathrm{R}$ program tabulated the count of elevation points within each subcatchment at given depth intervals, creating a cumulative sum for each interval. This count of points was then multiplied by the area that each point represented, which was equal to the original DEM raster cell size. A constant area, equivalent to a standard $4 \mathrm{ft}(1.2 \mathrm{~m})$ diameter manhole, was assigned for all depths between the node invert and the lowest surface or basement storage elevation within the subcatchment. A list of all of these storage curves was then imported, as a text file, into the SWMM project's .inp file. Figure 3.7 below is an example of one of these storage curves as visualized in the SWMM GUI.

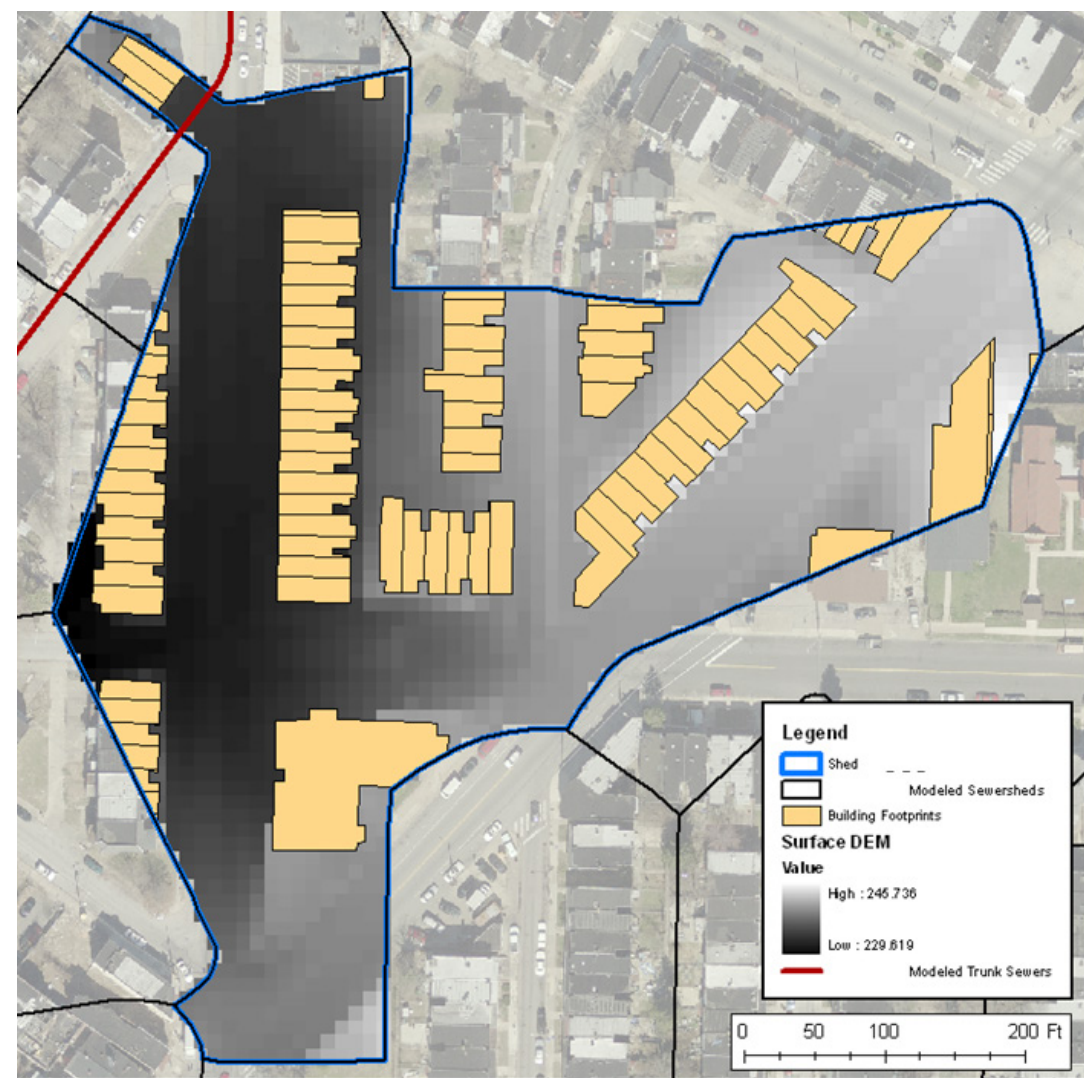

Figure 3.5 Building footprints overlaying elevation raster. 


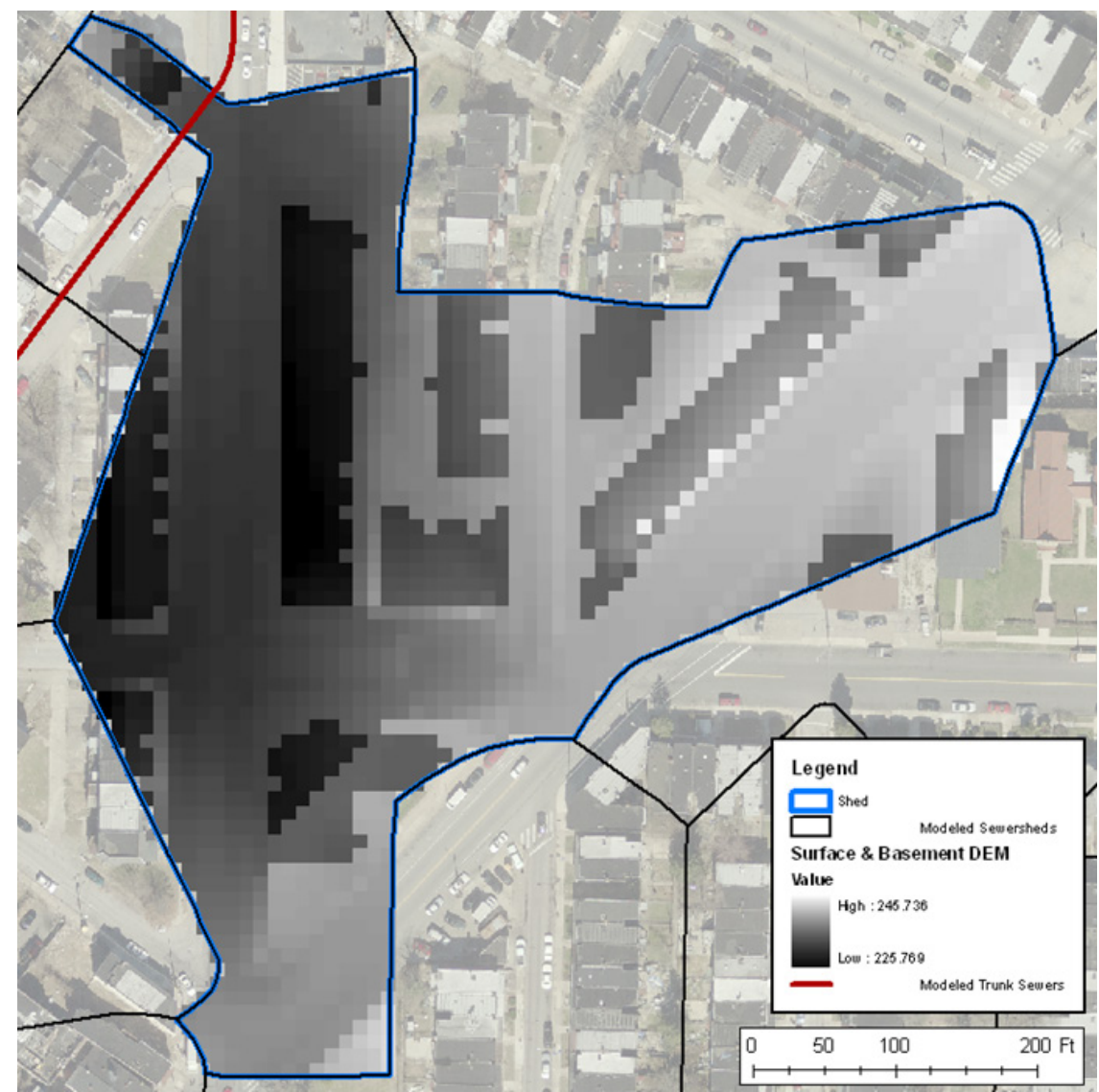

Figure 3.6 Raster DEM with $5 \mathrm{ft}(1.52 \mathrm{~m})$ basement depths burnt into the surface elevation.

Once storage curves were created for each subcatchment, the next stage was to determine where on the surface a subcatchment was hydraulically connected to its neighboring subcatchments.

1. Within GIS, convert a polygon shapefile of the subcatchment boundaries into a polyline shapefile. This process will create a different line segment wherever the polygons on either side of a boundary line are different. For example, if subcatchment Y is surrounded by eight other subcatchments, the boundary line for subcatchment Y will be split into eight line segments. Each of these line segments will be associated with the subcatchment on either side of the line segment; 


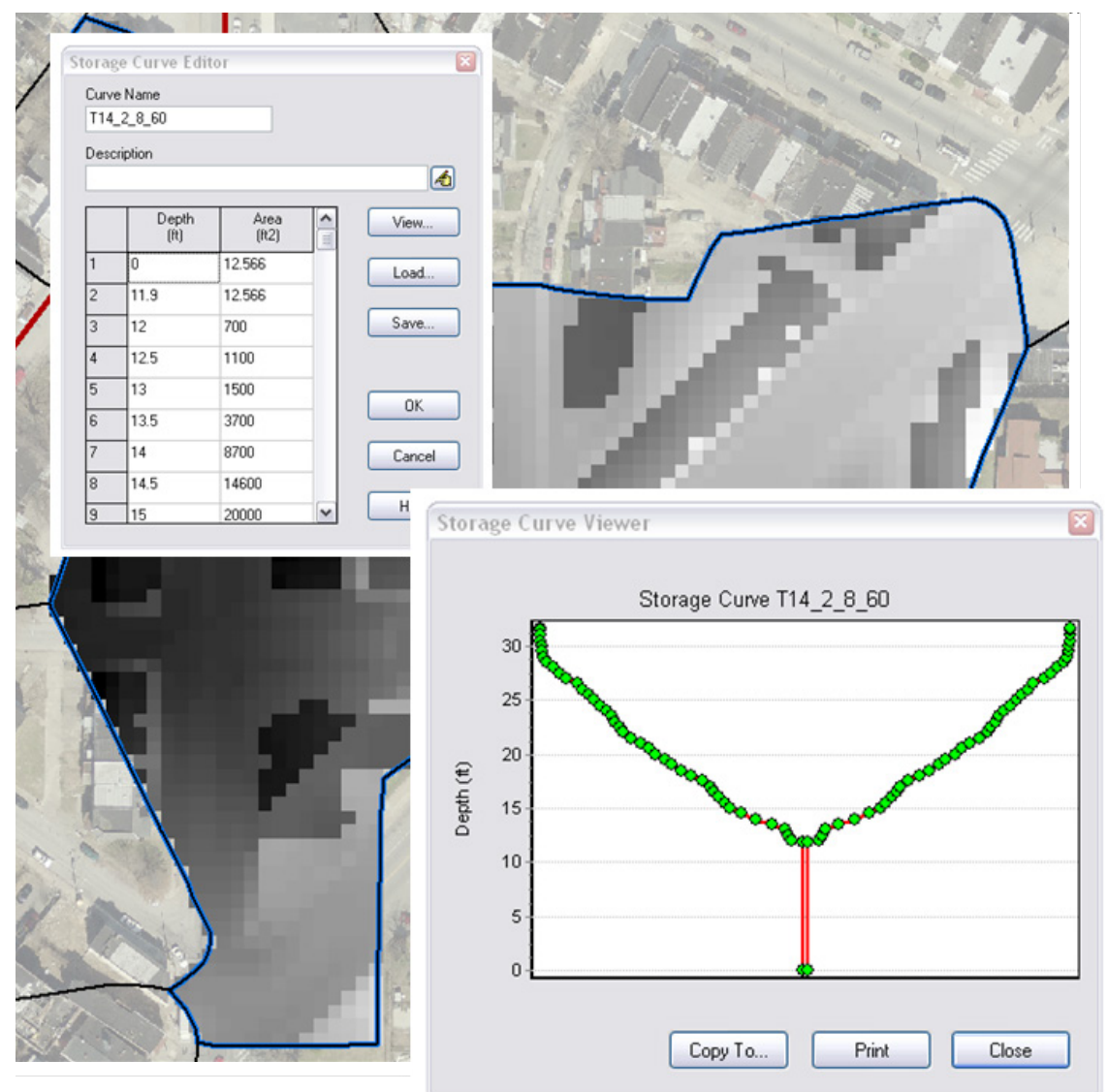

Figure 3.7 A sample depth-area curve for a storage node which serves as the outlet for a subcatchment's runoff.

2. Prepare contours from the DEM file (without burnt in basement depths) used in the storage curve creation process;

3. Intersect the subcatchment boundary line segments with the contours so that each an elevation profile of each line segment is easily generated;

4. Within a database program (e.g. MS Access) determine the minimum elevation point along each line segment. This low point is the connection elevation between the two subcatchments on either side of the line segment (Figure 3.8);

5. By relating the minimum elevation along the line segment to the invert of the subcatchment's representative storage node, 


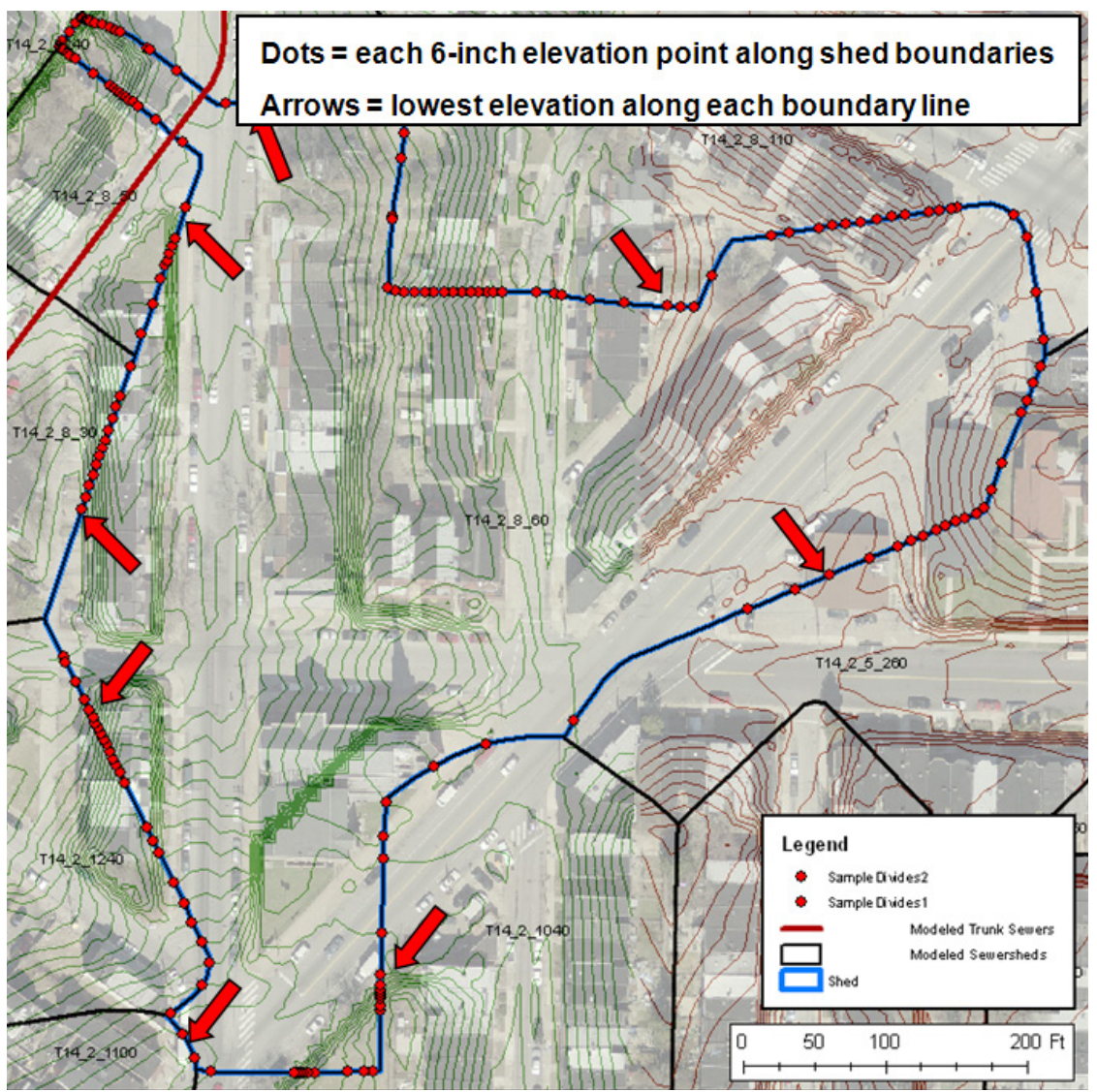

Figure 3.8 Locations of interconnections between a subcatchment and its eight surrounding subcatchments.

a height can be calculated which will serve as the inlet offset for the link representing this hydraulic connection between two subcatchments; and

6. For each of these surface connections, a link was added to the SWMM model; this would allow a storage node to pond water on the surface (or in basements) until the water depth reached the elevation, at which point it would spill over into a neighboring subcatchment.

Realistic link characteristics (slope, length, width, cross sectional area and roughness) could have been determined with further geoprocessing. However, due to time constraints and a lack of surface flow data (only anecdotal estimates of surface ponding were available), non-limiting weirs were chosen 
as the SWMM links which represent overland flow paths between adjacent surface flooding areas. All weirs were assigned a constant width of $100 \mathrm{ft}$ $(30.5 \mathrm{~m})$, a height of $5 \mathrm{ft}(1.5 \mathrm{~m})$, and a weir coefficient of 3.3. Figure 3.9 illustrates the extent of this model, which contained a total of 508 subcatchments, 15 junctions, 1 outfall, 522 storage nodes, 590 conduits representing the trunk sewers, and 1343 weirs representing surface flowpaths.

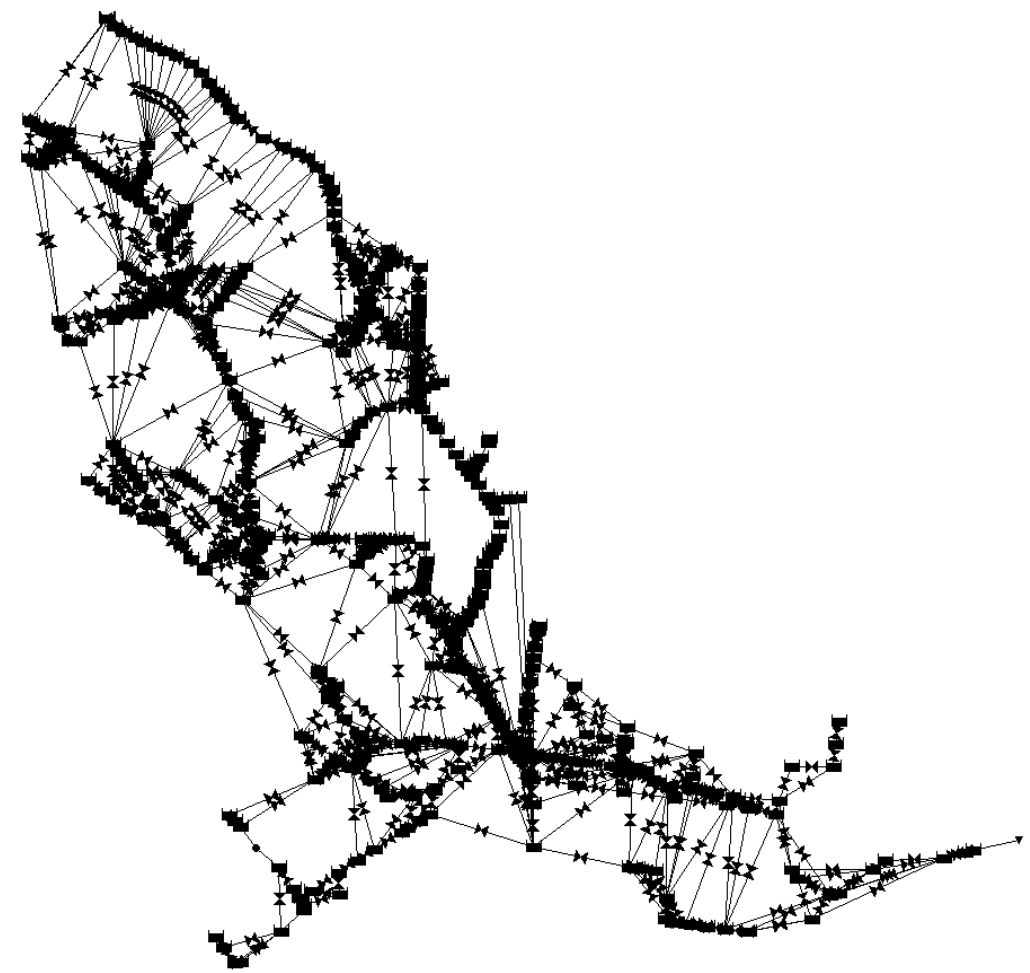

Figure 3.9 SWMM GUI visualization of model, complete with storage nodes, sewer conduits and surface flow conduits.

\subsubsection{Post-processing SWMM Results}

In order to visualize the location and depth of basement and surface flood inundation, a geoprocessing routine was used which visually redistributed the stored floodwaters from the depth-area curves. The area at any given elevation was conceptualized into the depth-area curves for calculations within SWMM; however, the flood depths were accurately assigned to the correct physical location within a subcatchment by comparing the DEM raster (with 
burnt-in basement depths) to each subcatchment's peak HGL elevation. A flood depth raster was created by subtracting the DEM from the peak HGL elevation. These flood depths were then joined with the building footprints data to determine the impact on each building was. Any flooded zones which were not associated with a building, were classified as surface flooding.

\subsection{Model Validation and Results}

Two validation steps were taken in order to quantify the error in model results. Flow monitors placed in sewers located throughout the project area were used to calibrate and validate hydrologic and hydraulic model parameters which were not directly known (or measurable) from existing data. The second validation step taken was to compare basement and surface flooding results to homeowner-submitted surveys, which provided anecdotal evidence of the location and severity of basement and surface flooding.

\subsubsection{Hydrologic and Hydraulic Model Validation}

In-pipe flow monitors recorded the HGL and mean pipe flow velocity at seven sites within the project area. The data from these monitors were used to refine the runoff prediction capabilities of this model. This was done through refinement of hydrologic parameters that cannot, or could not, be easily measured. These parameters included percent of impervious area routed over pervious area, depression storage, saturated soil hydraulic conductivity, and the subcatchment width (a parameter used to determine overland flow timing). By comparing monitored flow to predicted flow, model parameters can be evaluated and modified. Final model parameter values from the LTCPU model were used as the baseline conditions for this model.

Model predicted event volume and event peak flows were compared to observed flow monitoring data. Figure 3.10 shows the observed modeled hydrographs at one monitor location for hurricane Irene (2011 08 27). Figure 3.11 shows the same for tropical storm Lee (2011 09 07). These two events were the largest events recorded during the monitoring period; both are known to have caused basement and surface flooding throughout the project area. As seen in the following figures, the model adequately reproduces the flow hydrographs.

In addition to hydrograph comparisons, observed runoff volumes and peak flow rates were compared to simulated results for all events. Figures 3.12 and 3.13 are examples of these comparisons at one monitoring location for the two large events of 2011. 


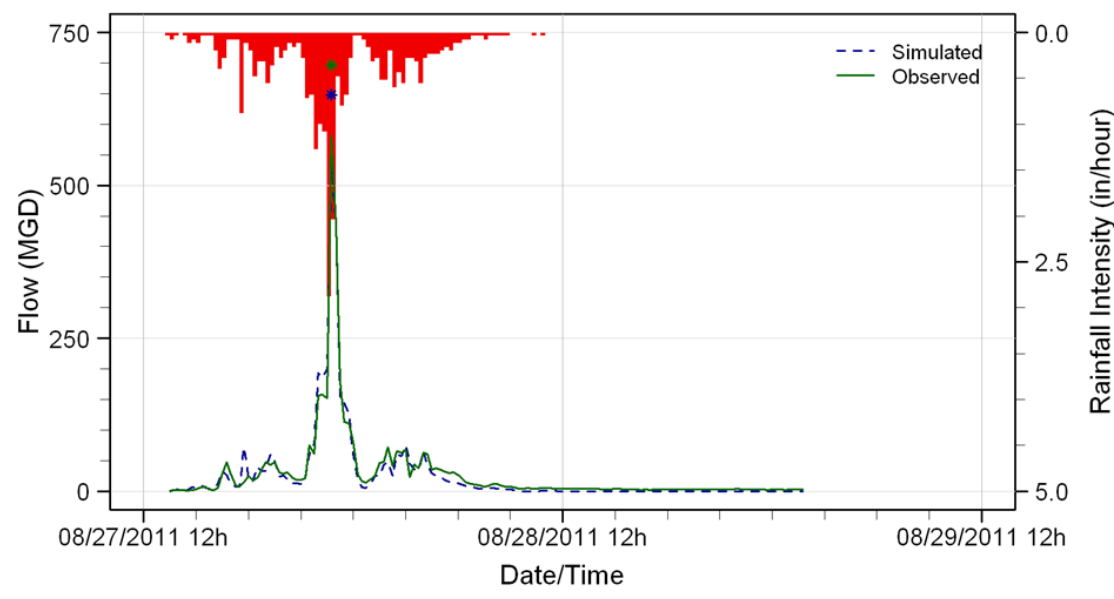

Figure 3.10 Rainfall hyetograph (top axis) and simulated and observed hydrographs at one flow monitor for 20110827 (total observed rainfall was $6.47 \mathrm{in} ., 16.4 \mathrm{~cm}$ ).

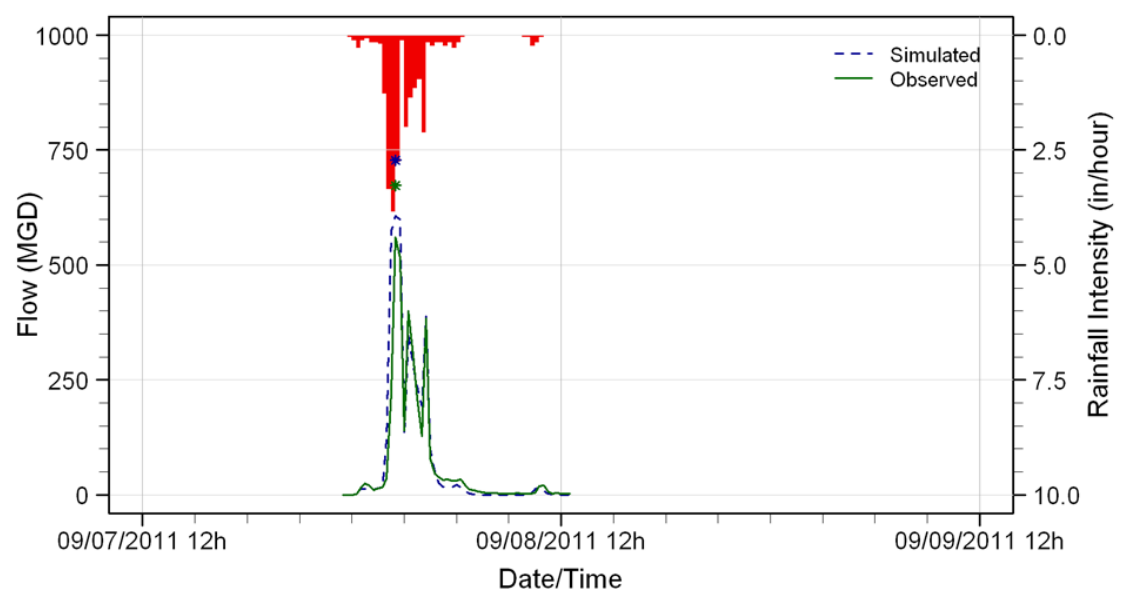

Figure 3.11 Rainfall hyetograph (top axis) and simulated and observed hydrographs at one flow monitor for 20110908 (total observed rainfall was 5.56 in., $14.1 \mathrm{~cm}$ ). 


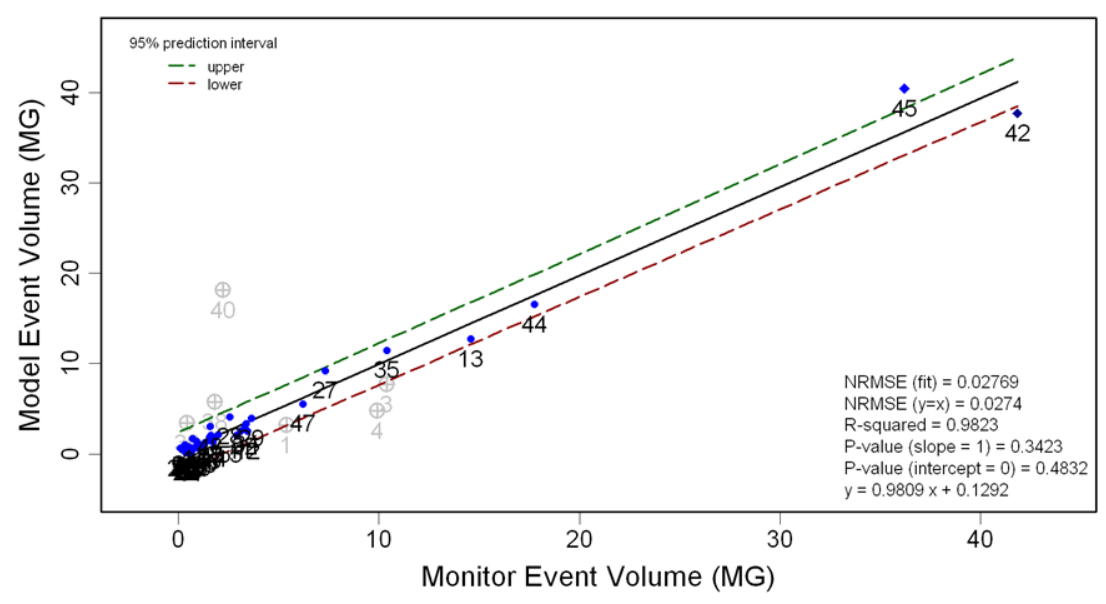

Figure 3.12 Scatter plot of predicted versus observed event volumes at one monitor for 53 monitored events (gray icons indicate events removed from analysis due to spatially varied rainfall or snowmelt).

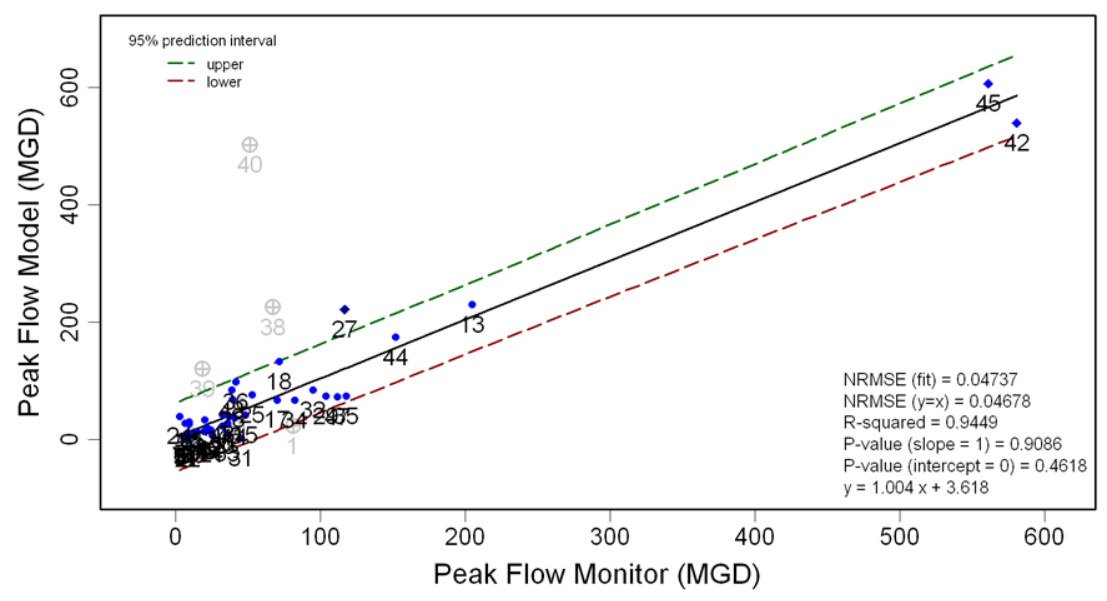

Figure 3.13 Scatter plot of predicted versus observed peak flow rates at one monitor for 53 monitored events (gray icons indicate events removed from analysis due to spatially varied rainfall or snowmelt). 
These plots were created at each monitoring location, and a regression analysis was completed to quantify the model's performance at each location. Each location's modeled vs observed data was fitted with a line of best fit. The slope, $\mathrm{y}$-intercept, and correlation coefficient $\left(R^{2}\right)$ were all calculated for the line of best fit. The model would perfectly match observed results if the line of best fit's slope $=1$, the $y$-intercept $=0$, and $R^{2}=1$. Table 3.2 provides all of these regression values for the seven monitoring locations. Note that two of the sites (T14-000345 and T14-013985) did not capture a significantly large enough number of wet weather events. A post-processing $\mathrm{R}$ program, developed by Rajan and Artita (2011), was used to systematically evaluate the model results.

Table 3.2 Regression statistics for simulated vs observed volume and peak flow rate results.

\begin{tabular}{cccccccc}
\hline & & \multicolumn{3}{c}{$\begin{array}{c}\text { Event Volume } \\
\text { Validation Results }\end{array}$} & \multicolumn{3}{c}{$\begin{array}{c}\text { Event Peak Flow Rate } \\
\text { Validation Results }\end{array}$} \\
Site & \# events & Slope & Intercept & $R^{2}$ & Slope & Intercept & $R^{2}$ \\
\hline T14-000345 & 13 & 0.97 & 1.02 & 0.79 & 0.49 & 22.93 & 0.56 \\
T14-000490 & 58 & 0.92 & 0.15 & 0.76 & 0.73 & 10.14 & 0.45 \\
T14-013940 & 39 & 0.99 & 0.02 & 0.97 & 1.09 & 4.65 & 0.68 \\
T14-013985 & 8 & 1.22 & -0.36 & 0.4 & 0.48 & 10.48 & 0.27 \\
T14-014030 & 53 & 0.98 & 0.17 & 0.94 & 1.04 & 1.97 & 0.71 \\
T14-023480 & 30 & 1.03 & 0.02 & 0.81 & 0.92 & 5.89 & 0.31 \\
T14-029300 & 29 & 0.94 & 0.05 & 0.84 & 0.76 & 3.26 & 0.47 \\
\hline
\end{tabular}

Simulated $=$ Slope $\times$ Observed + Intercept

Shaded monitors did not have an adequate number of events and were not included in analysis.

In a further attempt to quantify model uncertainty, potential sources of observed data error and model prediction error were estimated. This was followed by an attempt to identify the sources of the model error (James, 2003).

Two obvious sources of potential error in observed data are rainfall and flow monitoring data. Other sources of observed data error could have been introduced by the misrepresentation of existing hydraulics due to a lack of accurate, up-to-date engineering drawings. Model output error would account for other sources of error such as: inaccurate model parameter estimates (e.g. soil properties, surface roughness), spatial resolution of the model, and simplification of the pipe network.

Due to large areas covered by rain gauges in the project area (there are a total of four rain gauges available), spatially varied events could have potentially produced errors in rainfall estimates used in the model. Spatially varied thunderstorms were identified and removed from the validation analysis. Additionally, all snow events, and events influenced by snowmelt were removed 
as the model does not reproduce snowmelt accurately. It is assumed that these efforts have reduced rainfall error compared to the error documented by the manufacturer. Currently, the rain gauge network is calibrated and maintained such that the maximum allowable error in precipitation prediction is $\pm 5 \%$ (based on the manufacturer's documentation). This is likely an underestimate of the error introduced through the precipitation data.

Error in acceptable flow monitoring data is assumed to be around $\pm 15 \%$, according to a flow monitoring contractor.

Based on the flow monitoring results presented in Table 3.3, error in model predictions of runoff volume (at a $95 \%$ prediction interval) is estimated to be between $\pm 6 \%$ and $\pm 25 \%$. Assuming a combined error of $20 \%$ is introduced through precipitation and flow monitoring data, the model introduces from 0 to $5 \%$ error in the prediction of event volume.

Table 3.3 Error in volume, flow rate, and depth estimates.

\begin{tabular}{cccccc}
\hline \multirow{2}{*}{ Site } & \multirow{2}{*}{ \# events } & \multicolumn{3}{c}{ Validation Percent Error } & \multirow{2}{*}{ Depth Error } \\
& & Volume & Peak Flow Rate & Peak HGL & Depth \\
\hline T14-000345 & 13 & $40 \%$ & $40 \%$ & - & - \\
T14-000490 & 58 & $13 \%$ & $30 \%$ & $20 \%$ & \pm 15 in. $(38.1 \mathrm{~cm})$ \\
T14-013940 & 39 & $13 \%$ & $40 \%$ & $40 \%$ & \pm 20 in. $(50.8 \mathrm{~cm})$ \\
T14-013985 & 8 & $100 \%$ & $100 \%$ & $40 \%$ & \pm 10 in. $(25.4 \mathrm{~cm})$ \\
T14-014030 & 53 & $6 \%$ & $8 \%$ & $24 \%$ & \pm 33 in. $(83.8 \mathrm{~cm})$ \\
T14-023480 & 30 & $25 \%$ & $100 \%$ & $25 \%$ & \pm 10 in. $(25.4 \mathrm{~cm})$ \\
T14-029300 & 29 & $20 \%$ & $25 \%$ & $25 \%$ & \pm 5 in. $(12.7 \mathrm{~cm})$ \\
\hline
\end{tabular}

Shaded monitors did not have an adequate number of events and were not included in analysis.

Error in predictions of peak flow rates ranges from $\pm 8 \%$ to $\pm 40 \%$. The large variation in peak flow prediction between sensors is largely due to only a portion of the sensors recording the 20110827 and 20110907 flood events which were roughly an order of magnitude larger than most other storms in the dataset. The observed error ranges suggest that the model introduces from 0 to $20 \%$ error in prediction of peak flow rate.

The prediction of peak HGL (or flow depth) through an event is dependent on having accurate estimates of runoff volume and peak flow rates. However, uncertainty of pipe roughness estimates and simplifications of the modeled sewer system may further compound these errors when predicting flow depth. The error in predicted flow depth introduced by the model is estimated to be within $\pm 20 \%$.

A general interpretation of the above analysis, including Table 3.3, suggests that this model can predict peak HGL within $\pm 1.5 \mathrm{ft}(0.46 \mathrm{~m})$ at approximately a $95 \%$ prediction interval. 
Two tropical storm events used in the calibration dataset resulted in surface flooding; however, the monitors were not necessarily located directly in flooding areas. The $\pm 1.5 \mathrm{ft}(0.46 \mathrm{~m})$ uncertainty estimate, therefore, may not completely account for uncertainty introduced to the model via error in estimates of storage volumes and surface flow routing. These sources of uncertainty, which would be introduced to the model via error in surface contour estimates, cannot be defined at this time.

\subsubsection{Surface Model Validation}

Unlike the pipe flow validation discussed in the previous section, there was no source of quantitative data regarding surface flooding in the project area. However, a portion of residents in this project area responded to a survey regarding flooding in and around their properties, thereby providing some subjective information. This survey asked residents about the history of basement flooding at their property. Residents were also asked to provide information about known surface flooding in the streets and intersections in the vicinity of their homes. In total 234 surveys were returned, with 168 responding that basement backups had occurred on their property; many of the surveys also reported incidences of surface flooding in streets as well.

Figure 3.14 below provides an illustration of predicted flooding in relation to the reported basement and surface flooding in impacted portions of the modeled project area. Of the 168 parcels which reported flooding for a known flooding event on 201109 08, the median model results predicted that 113 of these parcels would have experienced basement flooding; for this event, the model has a flooding predictive accuracy of $67 \%$. Of the 66 parcels which reported no flooding on this event, the model correctly predicted that 29 parcels would not have flooded; this is a non-flooding predictive accuracy rate of $44 \%$ (Table 3.4).

Table 3.4 Flooding and non-flooding prediction accuracy (median peak HGL) for known flooding event on 20110908.

\begin{tabular}{lc}
\hline Flooded Parcel Prediction Accuracy $\approx 67 \%$ & \\
Total surveys & 234 \\
Surveys Reporting Flooding & 168 \\
\hline Accurately Predicted Flooding (median peak HGL) & $113(67 \%)$ \\
Accurately Predicted No Flooding (median peak HGL) & $29(44 \%)$ \\
\hline
\end{tabular}

For simplification, only predictions from the median peak HGL value are presented here. When used to estimate flooding damages, a range of damages was calculated based upon the estimated error in depth predictions of $\pm 1.5 \mathrm{ft}(0.46 \mathrm{~m})$, as discussed in the previous section. 


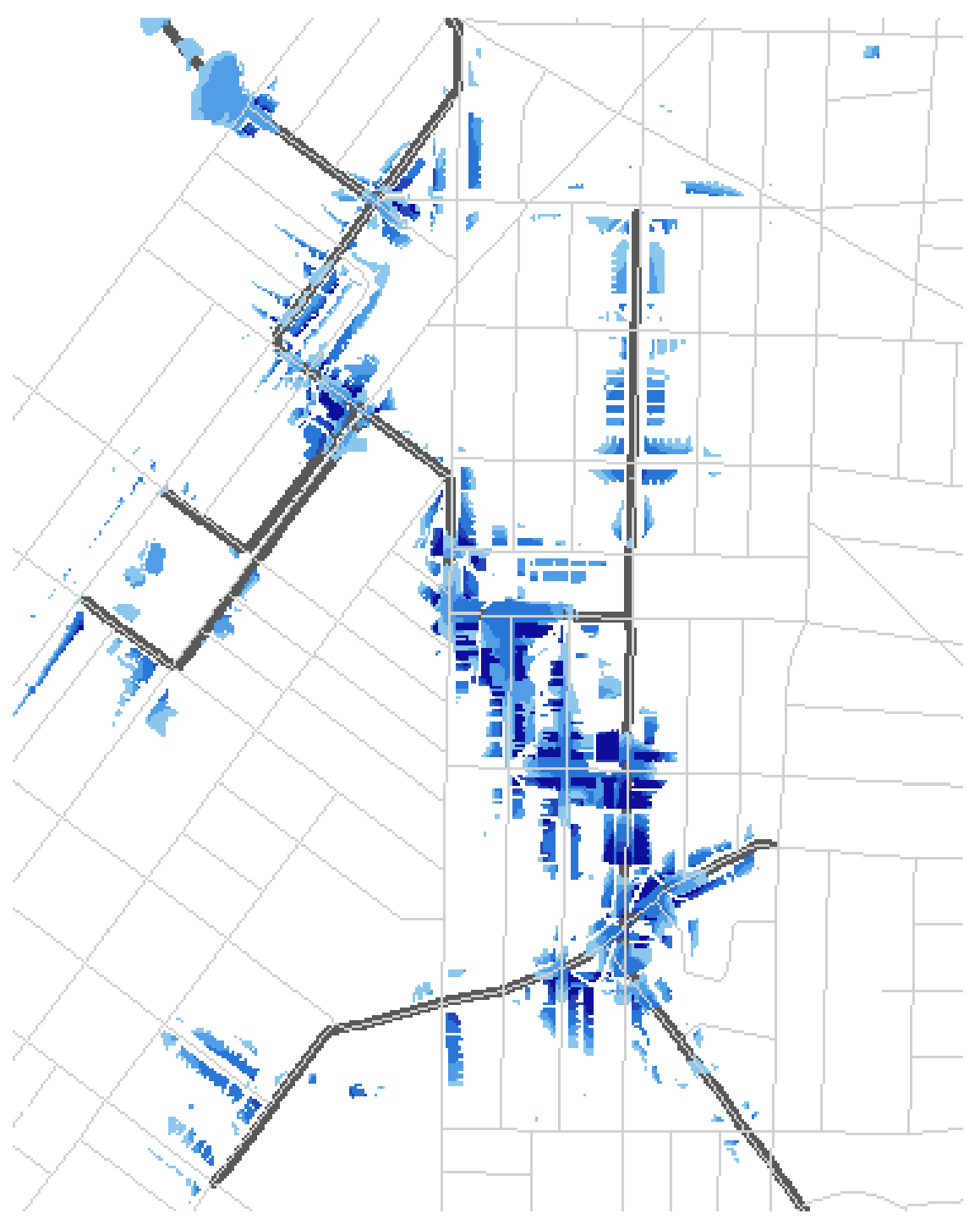

Figure 3.14 Predicted (median peak HGL) basement and surface flooding on 20110908 for one subset of the project. Darker regions correspond with deeper flood depths.

As shown in Figure 3.15, not every building owner in the area reported flooded basements. Some did not return surveys, while others may have reported a non-flooding property. In some cases, this could consist of one reported non-flooding building in the middle of an entire block of reported 
flooded buildings. There are numerous explanations behind why this may occur, such as: the installation of a backflow prevention device on the nonflooding property's service lateral, there was no basement; or there was a basement without any plumbing fixtures. Regardless of the reason for the nonflooding report, circumstances such as these will always be misrepresented with this modeling technique.

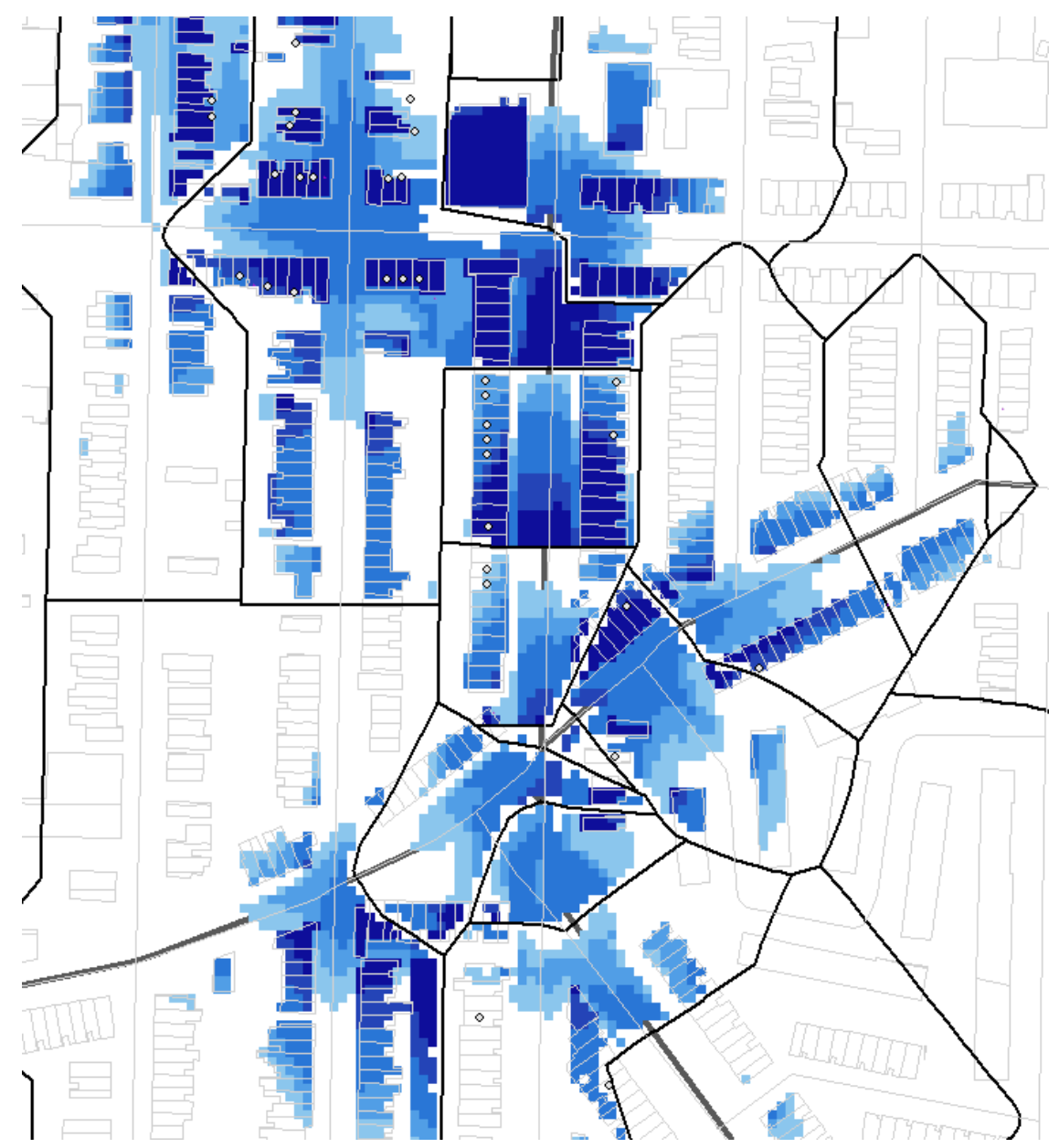

Figure 3.15 Property level predictions (median peak HGL) for flooding on 20110908 (darker regions correspond with deeper flood depths, dots correspond to parcels that have reported flooded basements). 


\subsection{Model Limitations}

While simple and straightforward, there are some limitations to the modelling approach that warrant discussion.

All buildings within the project area have basements that extend $5 \mathrm{ft}$ $(1.5 \mathrm{~m})$ below ground.

The assumption that all buildings had identical basements would result in under-predicted flood depths in basements that are actually deeper than $5 \mathrm{ft}$ $(1.52 \mathrm{~m})$ below the surface. This approach also likely over-predicted the system wide storage volume available in basements, since not all buildings have basements. The basement storage available also relied on the accuracy of the original geo-processing used to filter building elevations out of the DEM.

All points within a subcatchment at the same elevation have the same likelihood of flooding at any HGL elevation.

Regardless of a point's proximity to the trunk sewer, it will be available for storage (and flooding) at the same HGL as all other points within its subcatchment that are at the same elevation. This assumes a direct hydraulic connection between all points within the surface or basement flooding area. Any error introduced by this assumption would decrease with a decrease in subcatchment area. To account for this known source of model error, care was taken to keep subcatchments as small as possible in areas of known and/or predicted flooding.

The HGL elevation at the downstream end of each subcatchment defined the flooding elevation for that entire subcatchment.

The storage nodes were located at the downstream end of each subcatchment. This process assumed that all flooding within a given subcatchment was a function of the HGL within the trunk sewer at the downstream end of the entire subcatchment. The pipe slope as it traveled upstream through a subcatchment was not added to the flooding HGL elevation. This resulted in an under-prediction of flood depths at the upstream end of a subcatchment.

To minimize the effect of this known source of error, a maximum vertical drop for each subcatchment's sewer conduit was set. Any subcatchment which originally had a pipe slope that exceeded the allowable drop was split into smaller subcatchments.

Surface flow between subcatchments was simulated by flow across weirs.

Once surface flooding was indicated, the model routed floodwaters to surrounding subcatchments. This routing was modeled by weirs that connected 
each subcatchment at the minimum elevation bordering adjacent subcatchments. The weirs that were used allowed the flood depth to equalize between sheds; however, there was no time lagging of this routed floodwater. In reality, surface flood waves would be attenuated during routing. Therefore, this model likely over-predicted some flood depths.

The attenuation of the flood wave could be more accurately simulated by developing a surface conduit network that was more realistic than weirs. This approach would add complexity to the model, but there was not enough surface flooding data available to adequately calibrate and support such an approach. Without data to validate the surface flow, it was decided to err on the conservative side (i.e. favoring overprediction of flows) and immediately deliver the surface flow to the downstream subcatchment via weirs.

\subsection{Conclusions}

The geoprocessing routine outlined in this chapter proved to be a simple, accurate, and low cost method for determining location and magnitude of surface and basement flooding in a topographically varied urban area. While not as physically based as a full two dimensional model, the development of accurate surface connected storage units employed within a traditional SWMM model resulted in a high degree of spatial resolution in model predictions.

\section{References}

ESRI. 2012. ArcGIS Desktop 9.3 Help: Understanding Euclidean distance analysis.

James, W. 2005. Rules for Responsible Modeling 4th Edition. Ontario. CHI.

Philadelphia Water Department. 2009. Green City Clean Waters: The City of Philadelphia's Program for Combined Sewer Overflow Control - A Long Term Control Plan Update - Supplemental Documentation Volume 4 - Hydrologic and Hydraulic Modeling.

Rajan, R., K. Artita, J. Marge and J. Smullen. 2011. "Reformatting and Post Processing Tools for SWMM5." Journal of Water Management Modeling R245-19. doi: 10.14796/JWMM.R245-19.

Rossman, L.A. 2010. Storm Water Management Model User's Manual. USEPA EPA/600/R-05/097. 
